\title{
Quenching of nucleotide-derived radicals by bisbenzimidazole derivative Hoechst-33258 in aqueous solution
}

\author{
H MOHAN $^{\mathrm{a}}$, A ADHIKARY ${ }^{\mathrm{b}}, \mathrm{V} \mathrm{JAIN}^{\mathrm{b}}$ and J P MITTAL ${ }^{\mathrm{a}}{ }^{*}$ \\ ${ }^{a}$ Radiation Chemistry and Chemical Dynamics Division, Bhabha Atomic \\ Research Centre, Trombay, Mumbai 400 085, India \\ ${ }^{\mathrm{b}}$ Department of Biocybernetics, Institute of Nuclear Medicine and Allied \\ Sciences, Lucknow Marg, Delhi 110 054, India \\ e-mail: mittaljp@magnum.barc.ernet.in
}

MS received 14 February 2000; revised 20 April 2000

\begin{abstract}
The pulse radiolysis technique has been employed to investigate the reaction of DNA-minor-groove ligand bisbenzimidazole Hoechst 33258 with pyrimidine and purine nucleotide-derived radicals. Formation of an N-centred Hoechst-33258 radical is observed. Bimolecular rate constants and the yields of Hoechst-33258 radical have been evaluated. While the rate constant for the reaction of pyrimidine-derived radicals with Hoechst-33258 remained the same (1-2) $\times$ $10^{9} \mathrm{dm}^{3} \mathrm{~mol}^{-1} \mathrm{~s}^{-1}$, the yields of the Hoechst-33258 radical varied from $25 \%\left(5^{\prime}\right.$ cytidine monophosphate) to $75 \%$ (5'-guanosine monophosphate) under anoxic conditions. The rate constant values for the reaction of purine-derived radicals with Hoechst-33258, under oxic and anoxic conditions, remained the same whereas with pyrimidine-derived radicals, the rate constant value under oxic conditions was about two orders of magnitude lower than under anoxic conditions. The difference in the yields of Hoechst-33258 radical with various nucleotide-derived radicals suggest the formation of different types of radicals and that the reaction mainly occurs by electron transfer from Hoechst-33258 to the nucleotide radicals.
\end{abstract}

Keywords. Nucleotide-derived radicals; Hoechst-33258; pulse radiolysis.

\section{Introduction}

It is well-known that damage to DNA is the main cause for cell death, mutation and transformations induced by ionizing radiations. Studies to understand the mechanism of the induction of DNA lesions and their repair in a cell are important as they form the basis for predicting dose-response curves for biological effects induced by different types of radiations, and thereby enable the development of rational approaches to suitably modify radiation responses. Thus, radioprotectors to prevent radiation injuries to normal tissues, and radiosensitisers that enhance the damage in cancer cells can be developed, which may lead to improvements in radiotherapy protocols so that a high probability of cure is achieved without any significant side effects at a given radiation dose. Development of effective and non-toxic radiomodifiers is also of interest for space flights, nuclear industries and management of radiation-induced accidents ${ }^{1,2}$.

\footnotetext{
\#Also Honorary Professor at the Jawaharlal Nehru Centre for Advanced Scientific Research, Bangalore, India

*For correspondence
} 
It has been shown that DNA minor-groove-ligands like bisbenzimidazole derivatives (Hoechst-33258) provide significant protection against radiation-induced cytogenetic cell death and animal lethality without any serious side effects ${ }^{3-5}$. In order to elucidate the mechanism of radioprotection by these bisbenzimidazole compounds, measurements of radiation-induced strand breaks using aqueous solutions of DNA have also been carried out ${ }^{6,7}$. These in vitro studies showed that radiation-induced DNA-strand breakage was effectively reduced by low concentrations of Hoechst-33258 under oxic conditions. The mechanism by which these bisbenzimidazole derivatives protect DNA against radiationinduced strand breaks are complex and need to be investigated further ${ }^{4-6}$.

Previous pulse radiolysis studies on calf-thymus DNA in the presence of Hoechst33258 under oxic conditions suggest that different mechanisms involving fast ( $\mu$ s range) and delayed ( $\mu$ s range) processes lead to the formation of Hoechst-33258 radicals ${ }^{7,8}$. Hydroxyl radical $\left({ }^{\circ} \mathrm{OH}\right)$ scavenging by DNA-bound Hoechst-33258 can occur rapidly and may constitute the fast process with a rate constant value of $1.1 \times 10^{9} \mathrm{dm}^{3} \mathrm{~mol}^{-1} \mathrm{~s}^{-1}$. Calculations using this experimentally determined value of the rate constant of ${ }^{\circ} \mathrm{OH}$ radical scavenging by DNA-bound Hoechst-33258, however, indicated that ${ }^{\circ} \mathrm{OH}$ radical scavenging alone would not explain the overall protection ${ }^{7,9}$. It was suggested that there could be substantial quenching of the DNA radicals by DNA-bound Hoechst-33258, which would also explain the observed delayed formation of Hoechst radicals in pulse radiolysis studies ${ }^{7,9}$. The rate constant of the slow process is estimated to be in the order of $10^{6} \mathrm{dm}^{3} \mathrm{~mol}^{-1} \mathrm{~s}^{-17,8}$. In order to elucidate the mechanism of these DNA-radical quenching reactions, pulse radiolysis studies on the reactions of Hoechst-33258 with radicals generated from individual nucleotides have been undertaken.

This paper reports on the rate constants of the reactions of Hoechst-33258 with various nucleotide-derived radicals under anoxic $\left(\mathrm{N}_{2} \mathrm{O}\right)$ conditions. Under these conditions, the contribution of $e_{\mathrm{aq}}{ }^{-} / \mathrm{O}_{2}{ }^{-}$would be negligible. It has been reported that a small fraction $(8 \%)$ of the biological inactivation of single-stranded $\phi x 174$ DNA could be due to $e_{\mathrm{aq}}{ }^{-10}$. Therefore, studies concerning the reaction between Hoechst-33258 and $e_{\mathrm{aq}}{ }^{-}$using pulse radiolysis technique are also reported in the present work.<smiles>CN1CCN(c2ccc3[nH]c(-c4ccc5[nH]c(-c6ccc(O)cc6)nc5c4)nc3c2)CC1</smiles>

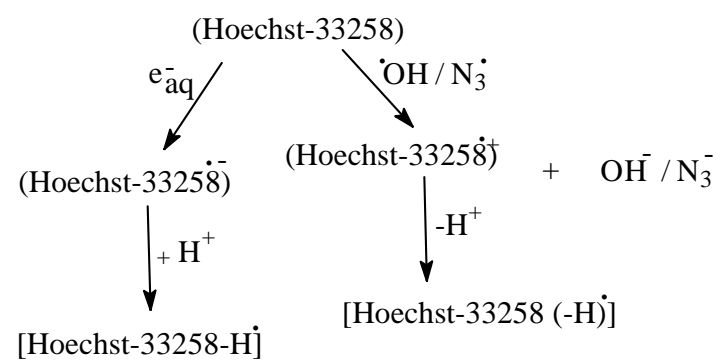

Scheme 1. Reaction of Hoechst-33258 with transient species. 


\section{Experimental}

\subsection{Materials}

Bisbenzimide, 2'-(4-hydroxyphenyl)-5-(4-methyl-1-piperazinyl)-2,5'-bi-1-H-benzimidazole trihydrochloride pentahydrate [Hoechst-33258, scheme 1], 5'-guanosine monophosphate (GMP), 5'-cytidine monophosphate (CMP), 5'-adenosine monophosphate (AMP), 5'-thymidine monophosphate (TMP), caffeine, guanine and hypoxanthine were obtained from Sigma Chemicals and used as received. All other chemicals used were also of high purity. The solutions were prepared in deionized 'nanopure' water and freshly prepared solutions were used in all experiments. Since buffers facilitate radiation-induced protonation/deprotonation reactions, the experiments were carried out in $10^{-3} \mathrm{~mol} \mathrm{dm}^{-3}$ phosphate buffer $(\mathrm{pH}=7)$.

\subsection{Pulse radiolysis measurements}

Pulse radiolysis experiments were carried out with high energy electron pulses ( $7 \mathrm{MeV}$, $50 \mathrm{~ns}$ ) obtained from a linear electron accelerator whose details are given elsewhere ${ }^{11,12}$. The dose delivered per pulse was determined with aerated aqueous solution of KSCN $\left(1 \times 10^{-2} \mathrm{~mol} \mathrm{dm}^{-3}\right)$ with $G \varepsilon=21,520 \mathrm{dm}^{3} \mathrm{~mol}^{-1} \mathrm{~cm}^{-1}$ per $100 \mathrm{eV}$ at $500 \mathrm{~nm}$ for the transient $(\mathrm{SCN})_{2}{ }^{--}$species. The $G$ denotes the number of species per $100 \mathrm{eV}$ of absorbed energy and $\varepsilon$ is the molar absorptivity of $(\mathrm{SCN})_{2}{ }^{--}$species at $500 \mathrm{~nm}$. The dose per pulse was close to $6 \mathrm{~Gy}$.

Radiolysis of $\mathrm{N}_{2}$-saturated neutral aqueous solution leads to the formation of three highly reactive species $\left({ }^{\circ} \mathrm{H},{ }^{\circ} \mathrm{OH}, e_{\mathrm{aq}}{ }^{-}\right)$, in addition to the formation of less reactive molecular products $\left(\mathrm{H}_{2}, \mathrm{H}_{2} \mathrm{O}_{2}\right)^{13}$,

$$
\mathrm{H}_{2} \mathrm{O} \rightarrow{ }^{\bullet} \mathrm{H},{ }^{\bullet} \mathrm{OH}, e_{\mathrm{aq}}{ }^{-}, \mathrm{H}_{2}, \mathrm{H}_{2} \mathrm{O}_{2}, \mathrm{H}_{3} \mathrm{O}^{+} .
$$

The reaction with ${ }^{\circ} \mathrm{OH}$ radicals was carried out in $\mathrm{N}_{2} \mathrm{O}$-saturated solutions where $e_{\mathrm{aq}}{ }^{-}$is quantitatively converted to ${ }^{\circ} \mathrm{OH}$ radicals with $G\left({ }^{\circ} \mathrm{OH}\right)=5.6$ and ${ }^{\circ} \mathrm{OH}$ radical is the main reactive species to react with the solute,

$$
\mathrm{N}_{2} \mathrm{O}+e_{\mathrm{aq}}{ }^{-} \rightarrow \mathrm{N}_{2}+{ }^{\bullet} \mathrm{OH}+\mathrm{OH}^{-}
$$

The reaction with $e_{\mathrm{aq}}{ }^{-}$was carried out in $\mathrm{N}_{2}$-saturated solutions in presence of $t$-butyl alcohol $\left(0 \cdot 2 \mathrm{~mol} \mathrm{dm}^{-3}\right)$ to scavenge ${ }^{\bullet} \mathrm{OH}$ radicals $\left(k_{3}=5 \cdot 2 \times 10^{8} \mathrm{dm}^{3} \mathrm{~mol}^{-1} \mathrm{~s}^{-1}\right)$,

$$
\left(\mathrm{CH}_{3}\right)_{3} \mathrm{COH}+{ }^{\bullet} \mathrm{OH} \rightarrow{ }^{\bullet} \mathrm{CH}_{2}\left(\mathrm{CH}_{3}\right)_{2} \mathrm{COH}+\mathrm{H}_{2} \mathrm{O} \text {. }
$$

Although $t$-butyl alcohol may not scavenge ${ }^{\circ} \mathrm{H}$ atoms completely $(k=1.7 \times$ $\left.10^{5} \mathrm{dm}^{3} \mathrm{~mol}^{-1} \mathrm{~s}^{-1}\right), t$-butyl alcohol radicals have very low redox potential value and can be considered inert in nature. The yield of ${ }^{\circ} \mathrm{H}$ atoms is also low $(G=0 \cdot 6)$ and their contribution is negligible. The reaction with $\mathrm{N}_{3}{ }^{\bullet}$ radical was carried out in $\mathrm{N}_{2} \mathrm{O}$-saturated solution of $\mathrm{N}_{3}^{-}\left(1 \times 10^{-3} \mathrm{~mol} \mathrm{dm}^{-3}\right)$ containing a low concentration of Hoechst-33258 $\left(1 \times 10^{-5} \mathrm{~mol} \mathrm{dm}^{-3}\right)$. Under these conditions, ${ }^{\circ} \mathrm{OH}$ radicals react only with $\mathrm{N}_{3}{ }^{-}$and the $\mathrm{N}_{3}{ }^{\bullet}$ formed then reacts with Hoechst-33258. ${ }^{\circ} \mathrm{OH}$ radicals do not react directly with Hoechst33258. 
The transient species formed on pulse radiolysis were monitored using a $450 \mathrm{~W}$ pulsed xenon arc lamp, monochromator (Kratos, GM-252) and a Hamamatsu R-955 photomultiplier as the detector. The photomultiplier output was digitized with a $100 \mathrm{MHz}$ storage oscilloscope interfaced to a computer for kinetic analysis. Rate constant values were taken from the kinetic analysis experiments for which very good correlation was obtained between experimental and calculated results ${ }^{14}$. Bimolecular rate constants were determined from the linear regression plots of $k_{\mathrm{obs}}$ vs solute concentration for at least three experiments; the variation was within $\pm 10 \%$.

\section{Results and discussion}

Pulse radiolysis of $\mathrm{N}_{2} \mathrm{O}$-saturated aqueous solution of $\mathrm{N}_{3}^{-}\left(1 \times 10^{-3} \mathrm{~mol} \mathrm{dm}^{-3}\right)$ in presence of low concentration of Hoechst-33258 $\left(1.7 \times 10^{-5} \mathrm{~mol} \mathrm{dm}^{-3}\right)$ showed bleaching of the ground state absorption band at $340 \mathrm{~nm}$ with the formation of a transient band at $440 \mathrm{~nm}$ (figure 1). Bimolecular rate constants determined from the bleaching at $340 \mathrm{~nm}$ and formation at $440 \mathrm{~nm}$ for different concentrations of Hoechst-33258 gave similar values $(3 \pm 0 \cdot 3) \times 10^{9} \mathrm{dm}^{3} \mathrm{~mol}^{-1} \mathrm{~s}^{-1}$. The absorbance of the transient species formed by the reaction of $\mathrm{N}_{3}{ }^{\circ}$ and ${ }^{\circ} \mathrm{OH}$ radicals by Hoechst-33258 was the same, and remained independent of solute concentration, indicating that the transient species is formed in full yield. Under the present experimental conditions, the entire yield of ${ }^{\circ} \mathrm{OH}$ radicals must have reacted with $\mathrm{N}_{3}{ }^{-}$and the $\mathrm{N}_{3}{ }^{\circ}$ radical formed would have reacted completely with Hoechst-33258 to form the transient species. The molar absorptivity at $440 \mathrm{~nm}$ was determined and was $1 \times 10^{4} \mathrm{dm}^{3} \mathrm{~mol}^{-1} \mathrm{~cm}^{-1}$. Since the nature of the transient species formed on reaction of $\mathrm{N}_{3}{ }^{\bullet}$ radical with Hoechst-33258 was similar to that obtained on reaction of ${ }^{\circ} \mathrm{OH}$ radicals and assigned to the $\mathrm{N}$-centred Hoechst-33258 radical, the transient species (figure 1) is also assigned to the $\mathrm{N}$-centred radical (scheme 1).

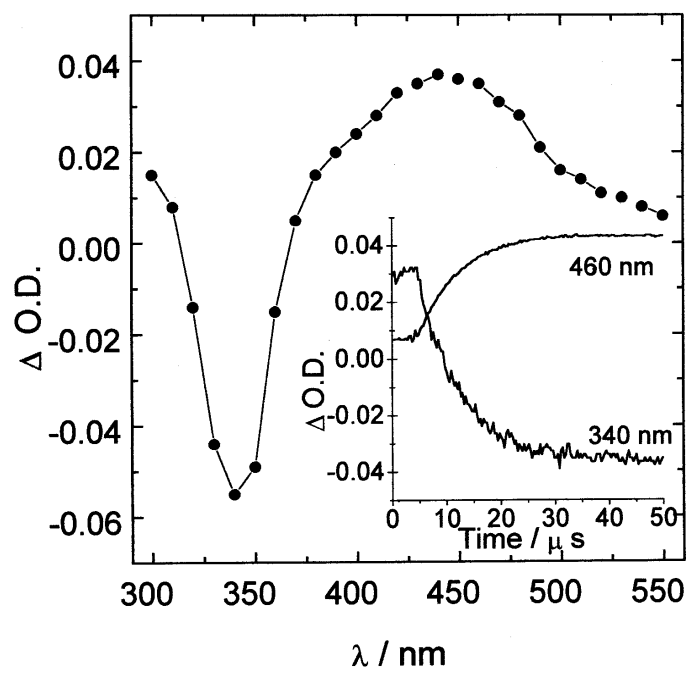

Figure 1. Transient absorption spectrum obtained on pulse radiolysis of $\mathrm{N}_{2} \mathrm{O}$ saturated aqueous solution of $\mathrm{N}_{3}^{-}\left(1 \times 10^{-3} \mathrm{~mol} \mathrm{dm}^{-3}\right)$ containing Hoechst-33258 $\left(1.7 \times 10^{-5} \mathrm{~mol} \mathrm{dm}^{-3}\right) 30 \mu \mathrm{s}$ after the pulse. Inset shows absorption-time profiles at 340 and $460 \mathrm{~nm}$. Dose per pulse $=6.4 \mathrm{~Gy}$. 


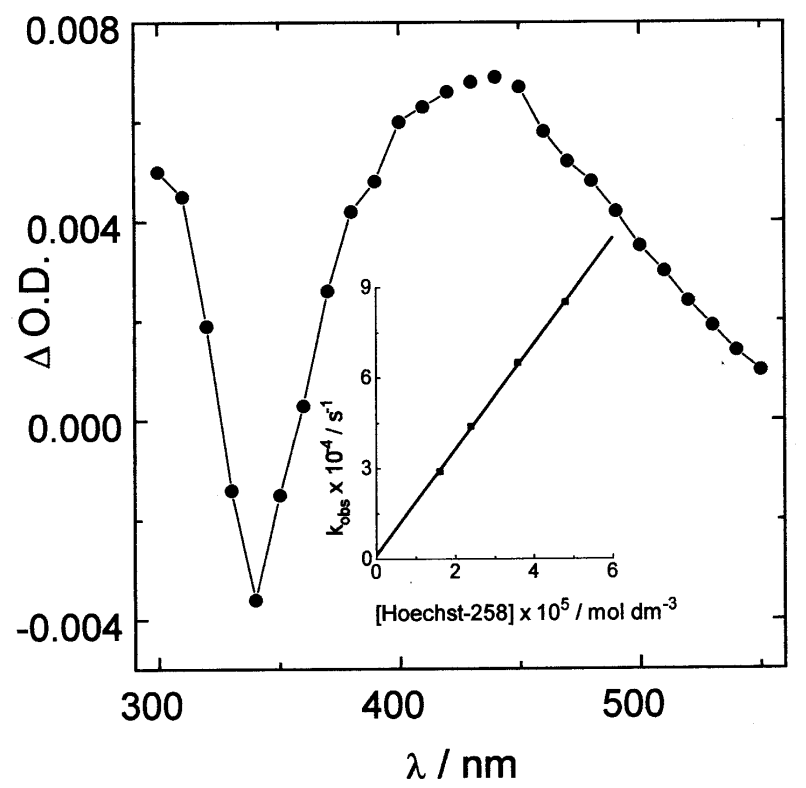

Figure 2. Transient absorption spectrum obtained on pulse radiolysis of $\mathrm{N}_{2} \mathrm{O}$ saturated aqueous solution of $5^{\prime}$-cytidine monophosphate $\left(1 \times 10^{-3} \mathrm{~mol} \mathrm{dm}^{-3}\right)$ containing Hoechst-33258 $\left(1.7 \times 10^{-5} \mathrm{~mol} \mathrm{dm}^{-3}\right) 10 \mu \mathrm{s}$ after the pulse. Inset shows variation of $k_{\mathrm{obs}}$ as a function of Hoechst-33258 concentration. Dose per pulse $=6 \cdot 4 \mathrm{~Gy}$.

Pulse radiolysis of $\mathrm{N}_{2} \mathrm{O}$-saturated aqueous solution of $5^{\prime}$-cytidine monophosphate $\left(1 \times 10^{-3} \mathrm{~mol} \mathrm{dm}^{-3}\right)$ containing low concentration of Hoechst-33258 $\left(1.7 \times 10^{-5} \mathrm{~mol} \mathrm{dm}^{-}\right.$ ${ }^{3}$ ) also showed the bleaching of ground state absorption at $340 \mathrm{~nm}$ with the formation of a transient absorption band at $440 \mathrm{~nm}$ (figure 2). The transient absorption spectrum was similar to that obtained on reaction of $\mathrm{N}_{3}{ }^{\circ}$ and ${ }^{\circ} \mathrm{OH}$ radicals. The spectrum (figure 2) is therefore also assigned to the $\mathrm{N}$-centred radical. The bimolecular rate constant was determined both from the bleaching of the ground state absorption at $340 \mathrm{~nm}$ and the formation of the band at $440 \mathrm{~nm}$. The value was observed to be the same $(1.8 \pm 0.4) \times$ $10^{9} \mathrm{dm}^{3} \mathrm{~mol}^{-1} \mathrm{~s}^{-1}$. Comparison of the absorbance value at $440 \mathrm{~nm}$ revealed that the yield of Hoechst-33258 radical is only $25 \%$. Similar studies have been carried out with a number of nucleotides and the bimolecular rate constants and yields of Hoechst-33258 radical obtained are shown in table 1.

In $\mathrm{N}_{2} \mathrm{O}$-saturated solutions, pulse radiolysis of nucleotides gives rise to two kinds of DNA-radicals: Heteroatom-centred purine radicals and C-centred pyrimidine-radicals (schemes 2 and 3$)^{15,16}$. Our results show that under anoxic conditions, the rate constants for the reaction of pyrimidine nucleotide-derived radical with Hoechst-33258 are of the same order of magnitude as those of the corresponding reactions between purine nucleotide-derived radicals and Hoechst-33258. Rate constants for the reaction of pyrimidine nucleotide-derived radicals and Hoechst-33258 under oxic conditions ${ }^{8}$ are, however, considerably lower (by about 2 orders of magnitude) than the corresponding rate constants under anoxic conditions. This observation indicates that the pyrimidineperoxyl radicals react with Hoechst-33258 at much slower rates than the C-centred 
pyrimidine radicals. Interestingly, rate constants for the reactions between purine nucleotide-derived radicals are of the same order of magnitude under oxic and anoxic conditions suggesting that the purine radicals do not react with oxygen. This is in agreement with the observation that heteroatom-centred purine-radicals do not react with oxygen ${ }^{16}$. The relative yields of Hoechst-33258 radicals (table 1) indicate that under anoxic conditions, all of the radiation-induced nucleotide radicals do not react with Hoechst-33258. The extent of radicals which accept electrons, oxidizing radicals, (C5-yl radical) produced in the case of pyrimidine nucleotides is about $20 \%{ }^{17}$. Since table 1 shows that under anoxic conditions, the relative yield of Hoechst-33258 radical formed due to the quenching of pyrimidine-nucleotide derived radicals is also similar, it is proposed that Hoechst-33258 reacts with C5-yl radicals in the case of pyrimidine nucleotides. In case of purine nucleotide, the yield of Hoechst-33258 is higher because the purine radicals could be both electron-donating and -accepting (redox ambivalent) ${ }^{15,18}$. In the case of adenine the A4-OH radical is a weak oxidant and

Table 1. Rate constants for the reaction of nucleotide-derived and $\mathrm{N}_{3}{ }^{\bullet}$ radicals with Hoechst-33258 and relative yields of Hoechst-33258 radicals under different conditions.

\begin{tabular}{lccccc}
\hline & \multicolumn{2}{c}{$\begin{array}{c}\text { Rate constant } \times 10^{-9} \\
\left(\mathrm{dm}^{3} \mathrm{~mol}^{-1} \mathrm{~s}^{-1}\right)\end{array}$} & & \multicolumn{2}{c}{$\begin{array}{c}\text { Relative yield of } \\
\text { Hoechst-33258 radical (\%) }\end{array}$} \\
\cline { 2 - 3 } \cline { 5 - 6 } Reaction & anoxic* & oxic** & & anoxic* & oxic**** \\
\hline CMP-derived radical + Hoechst-33258 & $1 \cdot 8$ & $0 \cdot 007$ & & 25 & 70 \\
TMP-derived radical + Hoechst-33258 & $2 \cdot 1$ & $0 \cdot 009$ & & 25 & 80 \\
GMP-derived radical + Hoechst-33258 & $1 \cdot 4$ & $1 \cdot 7$ & & 75 & 90 \\
AMP-derived radical + Hoechst-33258 & $1 \cdot 3$ & $2 \cdot 1$ & & 63 & 100 \\
OH radical + Hoechst-33258 & $9 \cdot 0$ & $9 \cdot 0$ & & 100 & 100 \\
$\mathrm{~N}_{3}$ + Hoechst-33258 & $3 \cdot 0$ & $3 \cdot 2$ & & 100 & 100 \\
\hline
\end{tabular}

*This work; **From reference 9; ***Unpublished work (A Adhikary, E Bothe, C von Sonntag, V Jain)

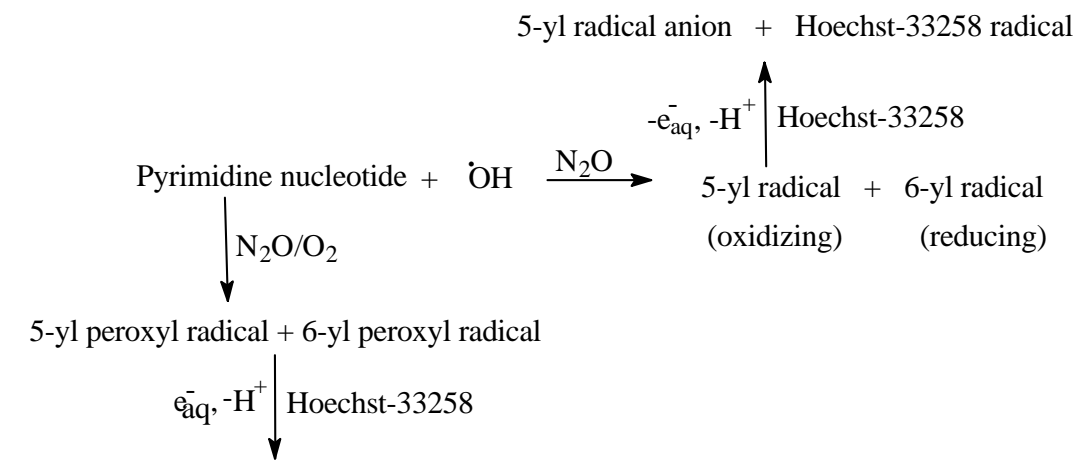

Hydroperoxide derivatives of 5-yl and

6-yl peroxyl radicals + Hoechst-33258 radical

Scheme 2. Reaction of pyrimidine radical with Hoechst-33258. 


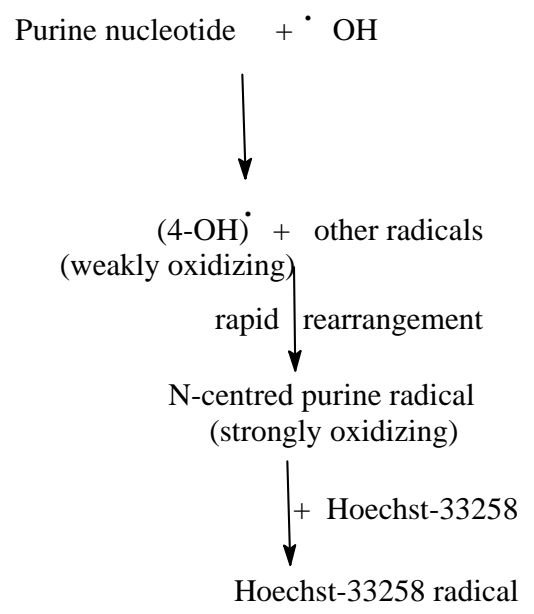

Scheme 3. Reaction of purine radical with Hoechst-33258.

ultimately gives rise to an $\mathrm{N}$-centred radical which is strongly oxidizing; $\mathrm{A} 8-\mathrm{OH}$ is redox ambivalent. In the case of guanine, the G4-OH radical is oxidizing. Moreover, purine nucleotide derived radicals could undergo rapid rearrangement reactions. Therefore, because of redox ambivalence and rearrangement reactions, all these purine nucleotidederived radicals are not quenched by Hoechst-33258.

Hoechst-33258 could quench the DNA-radicals by two possible mechanisms, (1) via $\mathrm{H}$-atom donation from Hoechst-33258, and (2) via electron transfer from Hoechst-33258 followed by a proton transfer. Recent pulse radiolysis studies with DNA are indicative of electron donation from Hoechst-33258 to DNA-radicals ${ }^{19}$. Therefore, quenching of pyrimidine and purine nucleotide-derived radicals by Hoechst-33258 could occur via electron transfer from Hoechst-33258 to the nucleotide-derived radicals leading to the formation of Hoechst-33258 radical cation and nucleotide radical anion. Subsequently a very rapid proton transfer could occur from Hoechst-33258 radical cation to the nucleotide radical anion leading to the formation of neutral Hoechst-33258 radical and nucleotide radicals (schemes 2, 3). The proton transfer has been proposed to occur because the spectra of neutral $\mathrm{N}$-centred Hoechst-33258 radicals are observed as a result of quenching of the nucleotide radicals (figure 2).

Rate constants for the reaction of purine-radicals with Hoechst-33258 (table 2), under anoxic conditions, have also been studied in guanine analogues (caffeine, hypoxanthene) to observe if changes in the purine ring system have any effect on these quenching reactions. It is observed that the rate constant for the reaction of hypoxanthene-radicals with Hoechst-33258 is less than those with caffeine- and guanine-radicals. Since caffeine and guanine have electron-donating groups in the purine ring system, the extent of electron-donation increases and hence the rate constant for the reaction of guanine and caffeine-derived radicals with Hoechst-33258 is expected to be higher than that for the reaction of the hypoxanthene-derived radical with Hoechst-33258. Under oxic conditions, both the C-5yl and C-6yl pyrimidine radicals form peroxyl radicals, which react slowly 
with Hoechst-33258 (table 1). These peroxyl radicals are electron-accepting in nature (oxidizing) and their quenching by Hoechst-33258 could occur via electron donation by Hoechst-33258 to the peroxyl radicals followed by very rapid proton transfer from the Hoechst-33258 radical cation to the peroxyl radical anion resulting in hydroperoxide formation (scheme 2). From the relative yields of Hoechst-33258 radicals, it is evident that all the pyrimidine peroxyl radicals may not be quenched by Hoechst-33258 and hence identification of the peroxyl radicals not quenched by Hoechst-33258 needs further investigation. However, comparison of relative yields of the Hoechst-33258 radical under oxic and anoxic conditions may imply that the protection provided by Hoechst-33258 could be lower under anoxic conditions.

The reaction of $e_{\mathrm{aq}}{ }^{-}$with Hoechst-33258 was studied by monitoring the decay of $e_{\mathrm{aq}}{ }^{-}$ at $700 \mathrm{~nm}$ as a function of Hoechst-33258 concentration. The decay followed pseudofirst-order kinetics, increasing with Hoechst-33258 concentration (figure 3). The bimolecular rate constant was determined to be $1.7 \times 10^{10} \mathrm{dm}^{3} \mathrm{~mol}^{-1} \mathrm{~s}^{-1}$. The probable site of electron addition could be the benzimidazole $\mathrm{N}$-atoms because $\mathrm{N}$-atom is the most

Table 2. Rate constants and yields of quenching of some of purine base analog derived radicals by Hoechst-33258 under anoxic conditions.

\begin{tabular}{lcc}
\hline Reactions & $\begin{array}{c}\text { Rate constant } \times 10^{-9} \\
\left(\mathrm{dm}^{3} \mathrm{~mol}^{-1} \mathrm{~s}^{-1}\right)\end{array}$ & $\begin{array}{c}\text { Relative yield of } \\
\text { Hoechst-33258 radical (\%) }\end{array}$ \\
\hline Guanine-derived radical + Hoechst-33258 & $1 \cdot 4$ & 75 \\
Caffeine-derived radicals + Hoechst-33258 & $0 \cdot 3$ & 60 \\
Hypoxanthine-derived radicals + Hoechst-33258 & $0 \cdot 2$ & 35 \\
Adenine-derived radicals + Hoechst-33258 & $1 \cdot 3$ & 62 \\
Ionosine-derived radicals + Hoechst-33258 & $0 \cdot 3$ & 22 \\
Purine-derived radicals + Hoechst-33258 & $1 \cdot 7$ & 43 \\
\hline
\end{tabular}

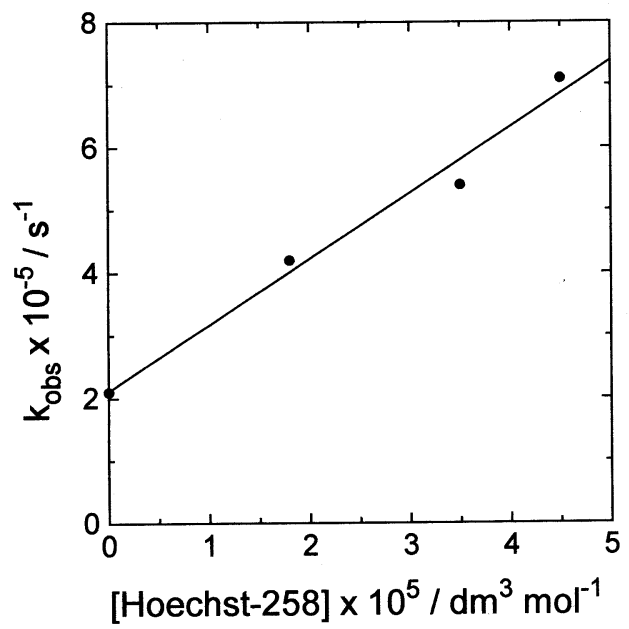

Figure 3. Variation of $k_{\mathrm{obs}}$ for the decay of $e_{\mathrm{aq}}{ }^{-}$for various concentrations of Hoechst-33258. 


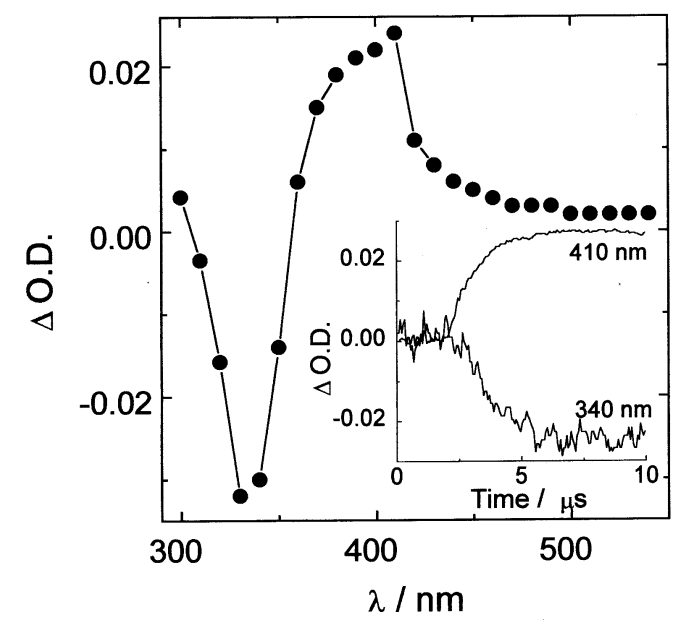

Figure 4. Transient absorption spectrum obtained on pulse radiolysis of $\mathrm{N}_{2}$-saturated solution of Hoechst-33258 $\left(3.4 \times 10^{-5} \mathrm{~mol} \mathrm{dm}^{-3}\right)$ containing $t$-butanol $\left(0.2 \mathrm{~mol} \mathrm{dm}^{-3}\right)$, $6 \mu$ s after the pulse. Inset shows absorption-time profiles at 410 and $340 \mathrm{~nm}$.

electronegative in Hoechst-33258 and the two benzimidazole rings and phenol ring in Hoechst-33258 lead to a large number of canonical structures of the electron adduct. The electron adduct formed is represented in scheme 1. Time-resolved studies showed the formation of a transient absorption band at $410 \mathrm{~nm}$ with bleaching at $340 \mathrm{~nm}$ (figure 4). Rate constant values determined from the formation $(410 \mathrm{~nm})$ and bleaching of the ground state absorption at $340 \mathrm{~nm}$ are also similar $\left(1.9 \times 10^{10} \mathrm{dm}^{3} \mathrm{~mol}^{-1} \mathrm{~s}^{-1}\right)$. The protonation of this electron-adduct gives rise to the formation of a neutral $\mathrm{N}$-centred $\mathrm{H}$ adduct of Hoechst-33258 (scheme 1). The nature of the transient absorption spectrum obtained on reaction of $e_{\mathrm{aq}}{ }^{-}$with Hoechst-33258 (figure 4) was different from that obtained on reaction of $\mathrm{N}_{3} \% \mathrm{OH}$ radicals with Hoechst-33258 (figure 1) and thus indicate the formation of different types of Hoechst-33258 radicals. The transient radical formed on reaction of $e_{\mathrm{aq}}{ }^{-}$with Hoechst-33258 is a $\mathrm{H}$-adduct, whereas that formed on reaction of $\mathrm{N}_{3}$ is a radical formed on deprotonation of solute radical cation (scheme 1).

\section{Conclusions}

Comparison of the relative yields of Hoechst-33258 radicals under oxic and anoxic conditions show that all nucleotide radicals do not react with Hoechst-33258. It is concluded that under anoxic conditions, Hoechst-33258 reacts only with electronaccepting (oxidizing) radicals and hence it is proposed that the quenching of DNAradicals by Hoechst-33258 occurs via electron donation from Hoechst-33258. Since the yields of Hoechst-33258 radicals formed by the quenching the nucleotide-radicals under anoxic conditions are less than the corresponding yields of Hoechst-33258 radicals under oxic conditions, lower radioprotection by Hoechst-33258 under anoxic conditions is expected. Increase in the rate constants and relative yields of Hoechst-33258 radicals on reaction of purine radicals containing electron-donating groups supports the conclusion that the reaction is by an electron-transfer mechanism. 


\section{References}

1. Sonntag von C 1987 The chemical basis of radiation biology (London: Taylor and Francis)

2. Jain V 1996 Indian J. Nucl. Med. 118

3. Singh S P, Jayanath V R, Chandan S, Dawarakanath B S, Singh S, Adhikary A and Jain V 1998 Indian J. Exp. Biol. 36375

4. Smith P J and Anderson C O 1984 Int. J. Radiat. Biol. 46331

5. Young S D and Hill R P 1989 Br. J. Cancer 60715

6. Martin R F and Denison L 1992 Int. J. Radiat. Oncol. Biol. Phys. 23579

7. Adhikary A, Bothe E, Jain V and Sonntag von C 1997 Radiat. Prot. $32 \mathrm{C} 1$

8. Adhikary A, Bothe E, Sonntag von C and Jain 1997 Radiat. Res. 148493

9. Adhikary A and Jain V 1997 Indian J. Biochem. Biophys. 34409

10. Nabben F J, Karman J P and Loman H 1982 Int. J. Radiat. Biol. 4223

11. Guha S N, Moorthy P N, Kishore K, Naik D B and Rao K N 1987 Proc. Indian Acad. Sci. (Chem. Sci.) 49261

12. Priyadarsini K I, Naik D B, Moorthy P N and Mittal J P 1991 Proc. 7th Tihany Symp. on Radiat. Chem., Hungarian Chem. Soc., Budapest, p. 205

13. Spinks J W T and Woods R J 1990 An introduction to radiation chemistry (New York: Wiley) p 243

14. Panajkar M S, Moorthy P N and Shirke N D 1988 Programming a microcomputer for on-line data acquisition and processing in pulse radiolysis experiment. Part I, Kinetic parameters, BARC Report 1410

15. Sonntag von C 1991 The chemistry of free-radical-mediated DNA damage in physical and chemical mechanisms in molecular radiation biology (eds) W A Glass and M N Verma (New York: Plenum) p. 287

16. Sonntag von C 1992 Radiat. Phys. Chem. 39477

17. Deeble D J, Schulz D and Sonntag von C 1986 Int. J. Radiat. Biol. 49915

18. Breen A P and Murphy J A 1995 Free Radical Biol. Med. 181033

19. Anderson R F and Martin R F 1997 5th International Workshop on Radiation Damage to DNA Techniques, Quantitation and Mechanisms, Bownesson, Windermore, Lake District, UK 